\title{
Breathing Mixed-ligand MOFs - solvent exchange and sorption studies
}

\section{Nabanita Chatterjee, Nolwazi Gcwensa, Clive L. Oliver}

\author{
Centre for Supramolecular Chemistry Research, Department of Chemistry, University of Cape Town, South Africa
}

\section{clive.oliver@uct.ac.za}

Metal-organic frameworks (MOFs) have attracted widespread attention for their porosity and potential applications in separation chemistry, catalysis, molecular sensing and gas storage. [1] This class of materials are coordination polymers and may be 1-periodic, 2-periodic or 3-periodic. Firstly, we report a partially-fluorinated, 2-periodic MOF, $[\mathrm{Zn}(\mathrm{hfipbb})(\mathrm{bpt})]_{n} \cdot n\left(\mathrm{C}_{3} \mathrm{H}_{7} \mathrm{NO}_{2} \cdot n\left(\mathrm{H}_{2} \mathrm{O}\right)\right.$ where $\mathrm{H}_{2}$ hfipbb $=4,4^{\prime}$-(hexafluoroisopropylidene)bis(benzoic acid) and bpt $=4$-amino-3,5-bis(4-pyridyl)-1,2,4-triazole. This framework undergoes single-crystal-to-single-crystal in solvent exchange with ethanol, dichloromethane and N,N'-dimethylacetamide, respectively. The solvent-induced 'breathing' of the 2-periodic frameworks results in potential void spaces varying from 15.2$35.4 \%$.[2] In addition, we report the synthesis of a pair of isoreticular mixed-ligand MOFs, $\left[\mathrm{Zn}\left(\mu_{2}-\mathrm{ia}\right)\left(\mu_{2}-\mathrm{bpe}\right)\right]_{n} \cdot n \mathrm{DMF}$ and $\left[\mathrm{Zn}\left(\mu_{2}-\right.\right.$ mia) $\left(\mu_{2}\right.$-bpe $\left.)\right]_{n} \cdot n\left(\mathrm{C}_{3} \mathrm{H}_{7} \mathrm{NO}\right)$, where ia $=$ isophthalate, mia $=5$-methoxyisophthalate and bpe $=1$,2-bis(4-pyridyl)ethane.[3] Both structures consist of doubly interpenetrated 2-periodic frameworks. Despite a lower void space, one of the activated MOFs exhibits significantly higher sorption of carbon dioxide at $195 \mathrm{~K}$, illustrating that small changes in functional groups, even in structurally similar MOFs, may have a large effect on sorption properties.

[1] Zhou, H.; Long, J. R.; Yaghi, O. M. Introduction to Metal-Organic Frameworks. Chem. Rev. 2012, 112, 673-674.

[2] Chatterjee, N. and Oliver, C.L., Cryst. Growth Des. 2018, 18, 7570-7578.

[3] Gcwensa, N., Chatterjee, N., Oliver, C.L., Inorg. Chem. 2019, 58, 2080-2088.

Keywords: metal-organic frameworks, breathing, sorption 